\title{
PASOLINI E A METOdOLOGIA DE UM OLHAR SOBRE A PRODUÇÃO CULTURAL NA ROCINHA
}

\author{
Davison da Silva Coutinho \\ Pontifícia Universidade Católica do Rio de Janeiro \\ infprofessor@gmail.com \\ Nilton Gamba Junior \\ Pontifícia Universidade Católica do Rio de Janeiro \\ gambajunior@gmail.com
}

Resumo: Este artigo descreve o processo de elaboração do projeto de conclusão do curso de Design da Pontifícia Universidade Católica do Rio de Janeiro, intitulado - $O$ inverso dos estereótipos: a vivência do cotidiano social em uma comunidade chamada Rocinha. O projeto resultou o livro Um Olhar Sobre a Produção Cultural na Rocinha ${ }^{1}$ e, hoje, se desdobra em dissertação de mestrado baseada na obra teórica de Pier Paolo Pasolini. Toma por empréstimo o Design como instrumento de promoção e enriquecimento da cultura da favela da Rocinha. Apesar de uma recente visão "glamurizada" sobre as favelas, ainda são vistas por diversos setores sociais como local apenas de violência e marginalidade; ou ainda são valorizadas apenas pelos aspectos pitorescos que se apresentam. Toda essa inquietação motivou o desenvolvimento de um projeto de design que mostrasse, justamente, o que ainda não possuia visibilidade, produzido em um contexto de multiplicidade de experiências, de cidadania e produção cultural. O projeto teve como objetivo a validação da ideia de que o estereótipo pode ser desmistificado. Através da diversidade de fazeres promovidos por iniciativas de caráter cultural anulam, assim, uma possível visão individual depreciativa transformando-a em autoestima e, servindo como forma de enfrentamento de preconceitos. Em diálogo com a obra de Pier Paolo Pasolini diversos conceitos serão abordados, mas destacam-se aqui as noções de: Cultura

\footnotetext{
${ }^{1}$ COUTINHO, S. Davison. Um Olhar Sobre a Produção Cultural na Rocinha, Rio de Janeiro, Minister,
} 2013. 
Material, Pedagogia das Coisas, Naturalização, Fetiche e Semiologia da Realidade que contribuem para pensar em uma metodologia de projeto.

Palavras-chave: Cultura, Rocinha, Pasolini, Favela, Transformação social, Cidadania.

Abstract: This article describes the process of drafting the graduation of Design at Pontifícia Universidade Católica do Rio de Janeiro titled - The Reverse Stereotypes: the experience of everyday social life in a community called Rocinha. The project resulted in the book An idea at the cultural production in Rocinha ${ }^{1}$ and today unfolds in dissertation based on the theoretical work of Pier Paolo Pasolini. The project addresses the use of design as a tool to promote and enrich the culture of the favela of Rocinha. Despite of a recent "glamorized" insight into the slums, they are still seen by many social sectors, such as location just of violence and marginalization, or still are valued only by the picturesque aspects that present there. All this environment motivated the development of a design project that shows precisely what we do not have visibility but which is produced in a context of multiple experiences of citizenship and cultural production. The project aimed to validate the idea that the stereotype can be demystified through the diversity of doings, initiatives promoted by cultural, which offset a possible derogatory individual vision turning it on self-esteem, serving as a way of coping with prejudice. In dialogue with the work of Pier Paolo Pasolini, several concepts are covered, but we highlight here the notions: Material Culture, Pedagogy of Things, Naturalization, Fetish and Semiology of Reality that contribute to thinking a design methodology .

Keywords: Culture, Rocinha, Pasolini, Slum, Social transformation, Citizenship.

\section{INTRODUÇÃO}

O presente artigo trata da análise de um insumo do projeto $O$ Inverso dos Estereótipos: a vivência do cotidiano social em uma comunidade chamada Rocinha que objetivou o registro, em um livro ilustrado e fotográfico: Um Olhar Sobre a Produção Cultural na Rocinha, que mostra um pouco da cultura que circula na Rocinha e os aspectos do cotidiano dos moradores da comunidade. O objetivo foi mostrar à sociedade valores e aspectos culturais. São produzidos por seus moradores em artes 
plásticas, música, dança, esportes que dão vida ao titulo.
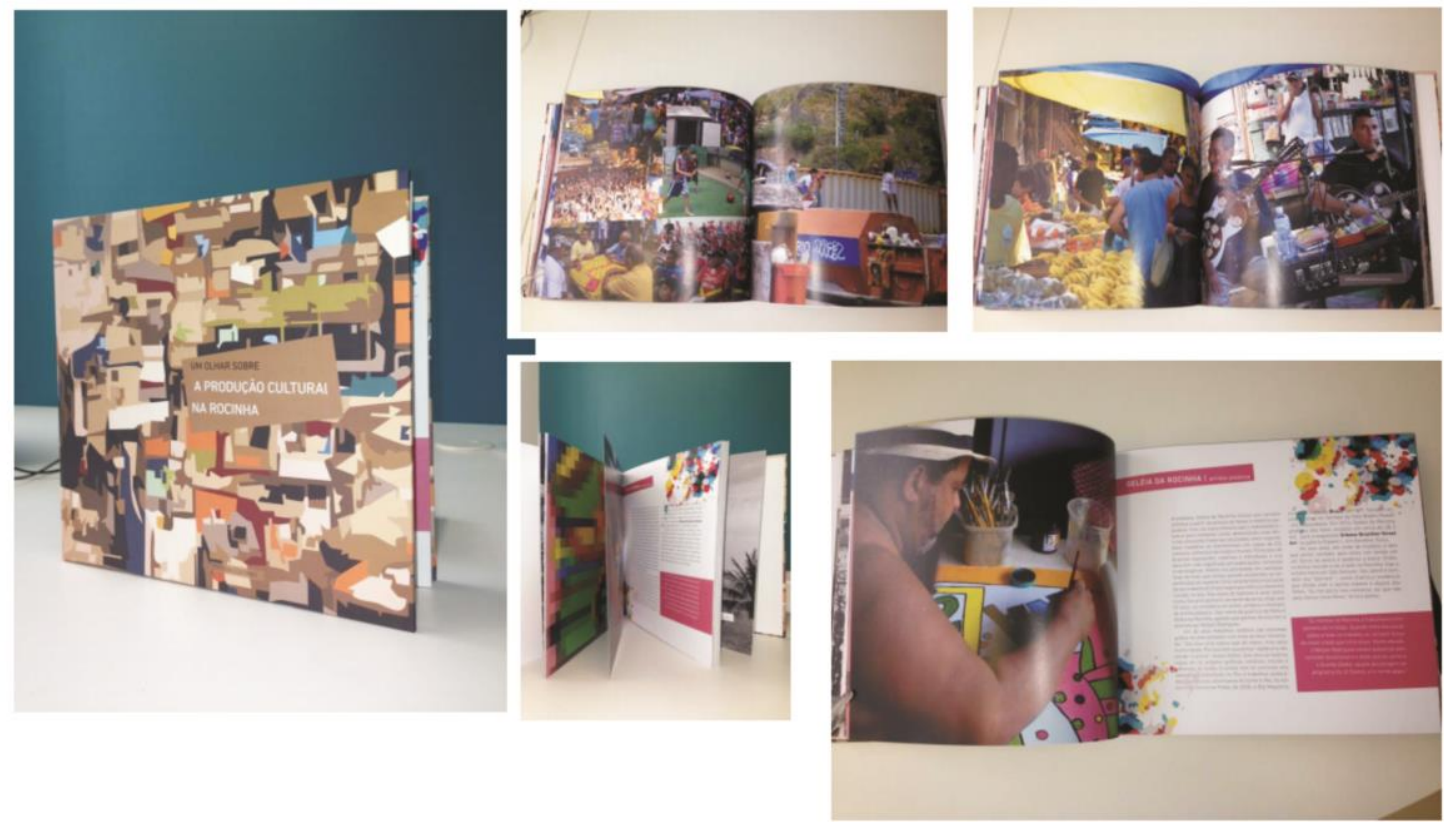

Figura 1 - partes do livro Um Olhar Sobre a Produção Cultural na Rocinha.

Em oposição à visão recorrente de estereótipos que incluem miséria, marginalização e ausência de cidadania, o projeto também apresenta imagens que mostram aspectos da relação de proximidade entre os moradores, tipos característicos da população local e infraestrutura das casas, ruas, becos e vielas e acervo comercial. A relevância de tal projeto inclui consequências de diversos espectros tais como, contribuir para uma melhor visibilidade do local, redução do preconceito e melhoria da autoestima dos moradores, além de incentivar o turismo no local.

Atualmente, o conteúdo organizado permitiu a proposição de uma pesquisa de mestrado cabendo a reflexão sobre sua metodologia, quando é publicado em artigo já em diálogo com um eixo principal para a reflexão sobre sua metodologia que é a obra de Pier Paolo Pasolini.

Não será possível apresentar o projeto como um todo, destacamos apenas algumas etapas da metodologia que evidenciam de maneira exemplar a relação direta com a obra de Pasolini. Selecionamos: a lacuna, as entrevistas, o registro e a veiculação.

\section{PIER PAOLO PASOLINI}

A obra de Pasolini é múltipla. Inclui projetos de diversas áreas tais como: cinema, poesia, desenho e teatro, além de ensaios e trabalhos teóricos. Sua produção teórica vai de ensaios até uma conceituação consistente sobre o que ele chama de Semiologia da Realidade na obra Empirismo Herético (2005). A relevância de sua obra conceitual para a área do Design é trabalhar com o conceito de Pedagogia Material e Linguagem Pedagógica das Coisas, que formula como um enfrentamento da linguagem visual e sua condição inarticulada, se comparada à linguagem textual. Apresenta-se 
também sua definição da dimensão fetichista de seu modelo de análise, que inclui não somente a participação do objeto e seu usuário, como também o total atravessamento dele mesmo, projetista, pelo objeto, ratificando o ato de questionar da neutralidade e do distanciamento.

Pasolini nasce em 1922 na Bologna. Assiste a ascensão e queda de Mussolini, a Segunda Grande Guerra e a euforia diante do capitalismo. Teve a maior parte de sua obra ficcional e teórica produzida entre os anos 1950 e 1970 e sua morte ocorreu em 1975.

Sua obra é construída propondo um olhar para esse contexto e com uma explícita preocupação biográfica e Histórica - o que remete ao fetichismo já mencionado. $O$ atravessamento histórico e a dimensão biográfica dão um aspecto formal particular à obra de Pasolini, impregnada de uma violência que reflete não só as tiranias, às quais assistiu, mas a sua maneira muito pessoal de reagir a elas, de igual maneira.

Outro foco da obra do autor é a periferia das condições hegemônicas, a população campesina ou a periferia urbana. Nesse artigo, demonstramos seu diálogo com um projeto realizado na Rocinha no Rio de Janeiro pelos dois aspectos: a atenção à cultura material e às comunidades.

\section{A FAVELA DA ROCINHA}

O surgimento da Favela da Rocinha foi iniciado em 1930, com os primeiros barracos e lavouras. Seu maior crescimento foi entre as décadas de ' 70 e ' 80 , transformando-a em uma das maiores favelas do Rio de Janeiro. Em 1995, a Rocinha é transformada em bairro e, a partir daí grandes investimentos e empreendimentos começam a compor este universo - hoje. Assim, chega o poder público juntamente com os serviços instalados em parceria com empresas privadas oferecem à população alguns tipos de assistência como: cursos, atendimento médico, atendimentos jurídicos, entre outros. Com relação à população da Rocinha, os moradores discordam dos dados revelados pelo Censo 2010 do IBGE afirmam que a Favela possui 69.161 habitantes. Para a Associação de Moradores da Rocinha, o número é de 180 a 200 mil.

A Rocinha é um grande celeiro de produções no que diz respeito à criação cultural. Porém, a produção cultural na comunidade, muitas vezes, não é reconhecida e chancelada. Faltam apoio e reconhecimento do poder público às diversas práticas culturais existentes. Os produtores enfrentam as mais diversas dificuldades para permanecerem funcionando e, promovendo o bem estar social aos moradores. A Cultura para a favela acaba sendo negligenciada pelos governantes. O fato é que a comunidade não quer mais apenas políticas assistencialistas. A fome e a sede de hoje, são, também, pela Arte, Educação e Cultura. Nestas ruas becos e vielas, o pouco vira muito em palco para a Arte, e a falta de infraestrutura não impede que as manifestações culturais persistam fortalecidas pelo ideal de se expressar, oferecendo uma vida mais interessante e com grande potencialidade sociocultural. 


\section{UM PROJETO PASOLINIANO}

"A educação que um menino recebe dos objetos, das coisas, da realidade física - em outras palavras, dos fenômenos materiais da sua condição social-, torna o corporalmente aquilo que é e será por toda a vida. O que é educada é a sua carne, como forma do seu espírito". Pasolini (1990)

As comunidades estão por todo o Rio de Janeiro e as barreiras entre elas e o asfalto vem sendo derrubadas. Ainda existe o preconceito por parte da sociedade que não entende de a favela precisar ser parte integrante da cidade e, não ser exterminada. O preconceito é originado pela falta de conhecimento, alimentado pelo medo do velho mito de que todo favelado é marginal. Apesar de uma recente visão com glamour sobre as favelas, elas ainda são representadas, por diversos setores sociais, como locais apenas, de violência e marginalidade. Ou ainda, são valorizadas apenas pelos aspectos pitorescos que se apresentam.

Pasolini, na coletânea Jovens Infelizes de Michel Lahud (1990) descreve o contexto da Itália, no inicio da segunda metade do século $X X$, logo a pós o fim da segunda-guerra mundial e, portanto, o fim do Fascismo de Musolini na abertura para o capitalismo de consumo, o que nos remete ao período próximo do surgimento e crescimento da favela da Rocinha. Como indica a epígrafe deste tópico, Pasolini vê na nova cultura material organizada, no entorno do consumo, um conjunto de segmentações, convenções e tiranias que seriam de visibilidade reduzida, por não estarem em nenhum manifesto político, redigido e passível de dialética. $O$ autor fala de uma linguagem menos articulada que a linguagem textual, e por isso, menos passível de argumentações, é a Linguagem das Coisas. Para entender o mito criado para o favelado, antes de mais nada, é fundamental entender sua linguagem, material e desarticulada - sobre o ponto de vista da argumentação meramente retórica.

"A condição social se reconhece na carne de um individuo (pelo menos na minha experiência histórica). Porque ele foi fisicamente plasmado justamente pela educação fisica da matéria da qual é feito seu mundo. As palavras dos pais, dos primeiros mestres e finalmente dos professores se sobrepõem ao que já ensinaram ao menino as coisas e os atos, cristalizando esse ensinamento" (Pasolini, 1990, p.120).

Para tanto, Pasolini vai propor uma Semiologia da Realidade, mas desenvolvida na sua obra Empirismo Herético (1978), mas desdobrada em toda sua obra. Outra afinidade da pesquisa com o autor é o campo de observação. Pasolini, como descrito anteriormente, se dedica a observação dos campesinos romanos e de populações que são marginalizadas pelo novo contexto socioeconômico.

“(...) colocar os jovens, em sua grande massa, numa situação histórica tal que os obrigue a viver a própria infelicidade sem que nada possa fazê-los vir a tomar clara consciência dela." (PASOLINI, 1990, p. 17).

Nesse momento, Pasolini confronta a noção de infelicidade com o capitalismo de consumo por intermédio das modificações nas sociedades rurais e das periferias. Aos poucos assumem um lugar de margem a um novo sistema que as exclui. Difere de outras formas de sistemas anteriores que se apoiavam em manifestos escritos 
contrapondo a força material e imagética desse novo sistema que aprisiona essa periferia em estereótipos e em infelicidades fundadas na desigualdade de consumo.

“(...) a cultura produz certos códigos; os códigos produzem certo comportamento; que o comportamento é uma linguagem; e que, num momento histórico em que a linguagem verbal é inteiramente convencional e esterilizada (tecnocratizada), a linguagem do comportamento assume uma importância decisiva." (PASOLINI apud LAHUD, 1993, p.46).

Além de falar do mesmo momento histórico das favelas no Brasil, Pasolini vai ser visionário ao defender que esse processo seria acelerado nas próximas décadas apontando assim, a importância de uma leitura da materialidade que o funda, o contrapõe ou gera novas alternativas.

\section{A METODOLOGIA}

O projeto selecionou grupos com atividades culturais na comunidade. $O$ conteúdo coletado por uma série de entrevistas com integrantes de vinte e cinco grupos culturais da Rocinha. O registro final teve como recorte, textos e imagens de onze grupos. Não só a dimensão material do conteúdo, a natureza material de sua difusão, implicou na metodologia de Design.

\section{Uma Lacuna}

O desenvolvimento do projeto aconteceu pela inquietação do estudante de Design e morador da Rocinha, frente à naturalização da visão do favelado e de seus estereótipos concebidos pela sociedade decide rever a produção cultural local. A naturalização aqui também retoma outro conceito de Pasolini que consiste em uma ilusão. Faz com que um ambiente social seja visto sem possibilidades de distanciamento e reflexões, enfim, acrítica. A naturalização, ao reforçar os estereótipos, gera uma aparência de igualdade e oculta a verdadeira desigualdade.

A necessidade de se desmistificar a ideia de que todo favelado é homogeneamente ligado a um único tipo de marginalidade coincidiu com a vontade pessoal do designer em transitar pelas vielas de sua própria comunidade e, se deparar com atividades culturais realizadas com improviso, criatividade e maestria. É então que retomamos a dimensão não neutra e totalmente implicada do designer. Quase como se pudéssemos pensar que parte da lacuna de projeto é um feitiche do designer como descrito por Pasolini. O autor diz que essa relação pessoal com o objeto pode ser muito importante ao estudá-lo e, principalmente, ao desnaturizá-lo:

"Meu amor fetichista pelas coisas do mundo impede-me de vê-las como naturais. Ele as consagra e desconsagra uma a uma: ele não as liga em sua fluidez exata, ele não tolera fluidez. Ele as isola e as idolatra com maior ou menor intensidade." (PASOLINI, 1983, p.140).

Pasolini apresenta três aspectos fundamentais de sua relação fetichista com a realidade e o conhecimento. $O$ primeiro é a descrença na unidade, na continuidade. $O$ 
segundo é a paixão e o envolvimento subjetivo que o afasta da neutralidade e da objetividade absolutas e, por último, a desnaturalização da realidade - consequência dos dois primeiros, pois é um desejo pessoal em mostrar a produção cultural da Rocinha que se transforma; reflexo de que alguns moradores também tenham necessidades de ver a homogeneização ser rompidos e, evidenciada tais aspectos positivos. A confirmação dessa predição é que suscitou as entrevistas que não só justificam e direcionam o projeto, como também fornecem os conteúdos da publicação.

Assim, surgiu o projeto de mostrar a sociedade que a Rocinha é muito mais que o já visto. Mostrar que a cultura tem o poder de transformar vidas e que precisa ser validada e chancelada dentro das comunidades como elemento de transformação social. Confirma-se o valor da imersão do Designer no campo.

\section{A Pesquisa}

As entrevistas foram semiestruturadas de abordagens informais com os produtores culturais. Tiveram como ponto de partida, assuntos relacionados ao tema (produção cultural local) sendo introdutório e com a finalidade de estabelecer, inicialmente, uma relação mais interpessoal e de confiança com o entrevistado, com o objetivo de se chegar a respostas mais espontâneas, deixando o mais receptivel aos questionamentos. Tal procedimento de entrevista se assemelha ao "Comizio $d$ ' Amore", documentário de Pasolini que tem como objetivo entrevistar pessoas de maneira direta e objetiva, a fim de se atingir e revelar a verdade mais profunda dos sujeitos (Lauhd 1993). Nesse trabalho Pasolini faz uso de perguntas divertidas e lúdicas, mas também de perguntas diretas e inconvenientes e, assim, consegue arrancar uma diversidade de reações. Nesse projeto, nos valemos de um modelo menos provocador, mas mais cativante, no entanto, mantendo o norte do trabalho do autor: atuar com o entrevistado in loco, no seu ambiente; permitir o fluxo diferenciado das respostas e evocando, junto ao discurso, referências materiais.

As abordagens aconteceram em lugares informais da comunidade; mais confortáveis e próximas para os entrevistados. Geralmente, os lugares de escolha eram aonde os mesmos realizavam seus trabalhos sociais, suas casas, ou algum lugar que consideravam importantes sobre a Rocinha.

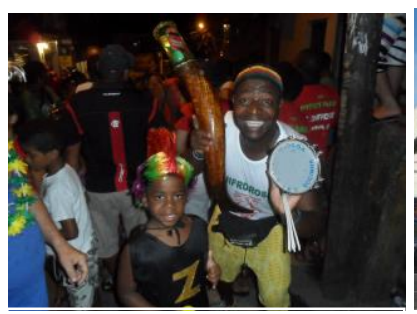

Figura 2 Bloco Chifrorosos

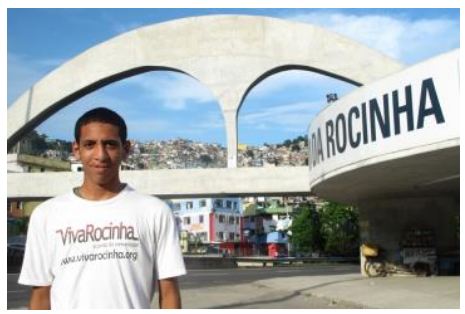

Figura 3 Michel Silva

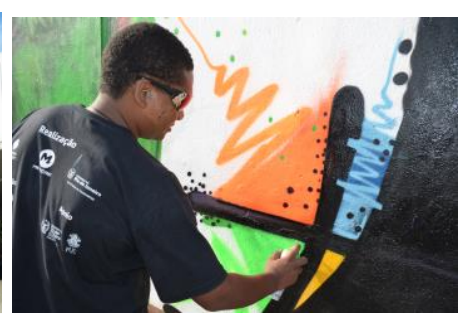

Figura 4 Artista Wark

As perguntas tinham um planejamento, mas não era um roteiro e, serviam como auxilio no direcionamento da entrevista. No entanto, o mais rico do processo foram as descobertas e revelações que cada entrevistado tinha. Suas particularidades acabaram gerando conteúdos diferentes. A pesquisa se define como semi-estruturada. 
Foi realizada com um roteiro que era mudado e seguia de acordo com o curso do diálogo.

Levantamos diversas possibilidades de conteúdo para apresentação no projeto. Tal levantamento foi classificado em quatro temas: convivência, produção cultural, infraestrutura e pessoas.

O que nos impressionou foi a vontade e o desejo dos entrevistados em contarem suas histórias, de forma personalizada como emergiu o projeto e sublinhando a dimensão biográfica descrita por Pasolini. Todos queriam participar e deixar registradas suas vidas e ações na memória histórica da Rocinha, confirmando a necessidade de contar suas histórias através da realidade em que vivem. O sonho, a expectativa e o futuro foram flecha certeira para a conclusão de nosso intento.

\section{Registro Fotográfico}

O livro produzido como véiculo do projeto se opõe ao enrijecimento cultural de certos modelos de representação abordada por Pasolini, por exemplo, ao enfatizar a linguagem imagética e não se limitar a um trabalho apenas textual ou teórico, tecnocratizado, portanto. Além de tudo, quando o texto utilizado é tratado em uma linguagem acessível, afastando de hermetismos acadêmicos, o que viabiliza ser acessado por um público mais amplo, incluindo a própria comunidade. Ou seja, desde o morador da Rocinha interessado em entender e conhecer o que é produzido em sua comunidade, até qualquer outra pessoa interessada em conhecer a produção cultural desenvolvida em uma favela, o conteúdo pode interessar leitores diversificados.

No texto Genariello: a linguagem pedagógica das coisas de Pasolini fica nítida a preocupação com binômio imagem-conhecimento. Processo que Pasolini confronta com o próprio aprendizado da criança. $\mathrm{O}$ aprendizado que ela recebe dos mestres, dos seus pais, dos jornais e da televisão podem ser sempre alterados ou colocados em dúvida, no entanto, o que aprendem com a linguagem pedagógica das coisas jamais pode ser esquecido ou mudado. É dessa descoberta do olhar para contruir a desnaturalização, agora por moradores convidados a participar das oficinas de registros fotográfico para a composição final do livro.

As fotografias no livro, ao final, são registros do Designer, de alguns moradores e de fotógrafos da Rocinha. Foram selecionadas entre as centenas de imagens as que pudessem transmitir o dia a dia dos moradores, que mostrassem essa forma de vida, com a originalidade de achar situações onde apesar de tantas dificuldades e lutas, os moradores estão solidários. Não era proposto causar um olhar de vitimização e sim de respeito e reconhecimento.

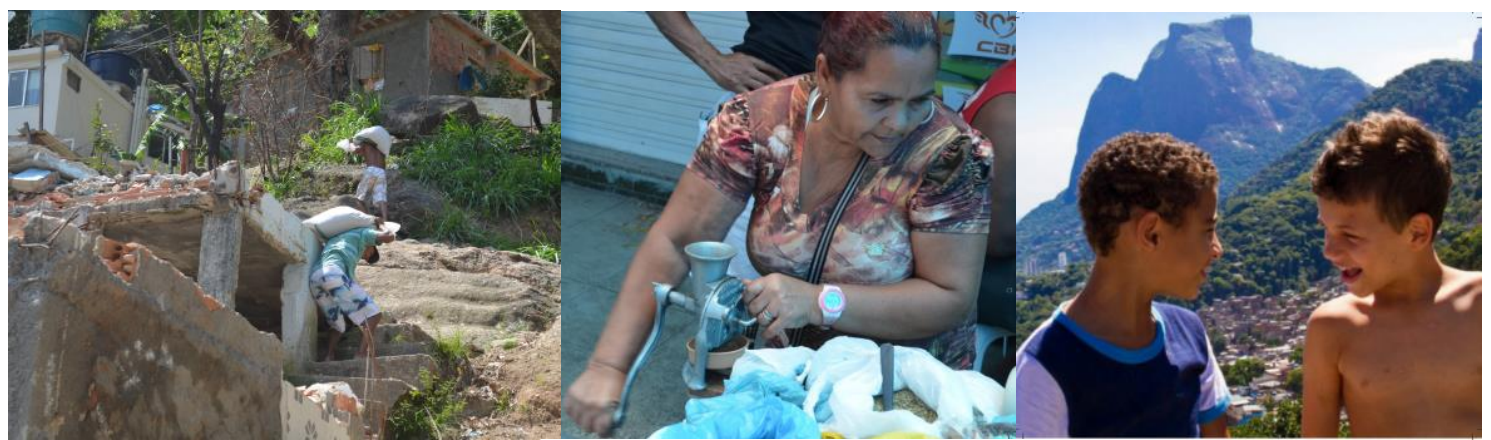

Figura 6 - Foto de morador (Joel Silva)
Figura 7 - Foto de fotógrafo local (Levi Ricardo) 
Segundo Pasolini, um mesmo lugar pode ser apresentado por diferentes olhares, dependendo de quem o está observando. Ele cita como exemplo os diferentes olhares sobre um lugar de um cineasta e de um literato. No nosso registro fotográfico tivemos como objetivo capturar imagens que pudessem representar a diversidade de significados do local, transmitindo sensações e interpretações que fugiam os limites da moldura de cada imagem e que provocavam no leitor um entendimento de uma cultura como um todo.

Iniciantes em fotografia, os moradores que participaram do projeto usaram uma máquina semiprofissional e aprenderam algumas técnicas básicas. Na Rocinha, em busca do que mostrar, oferecemos um olhar sem preconceito, podendo mostrar algumas situações e cenas de uma vida que julgamos ser tão diferentes e peculiares das vividas no "asfalto". Muitas vezes, parecidas como um sorriso ingênuo de uma criança em uma ciranda festiva de roda.

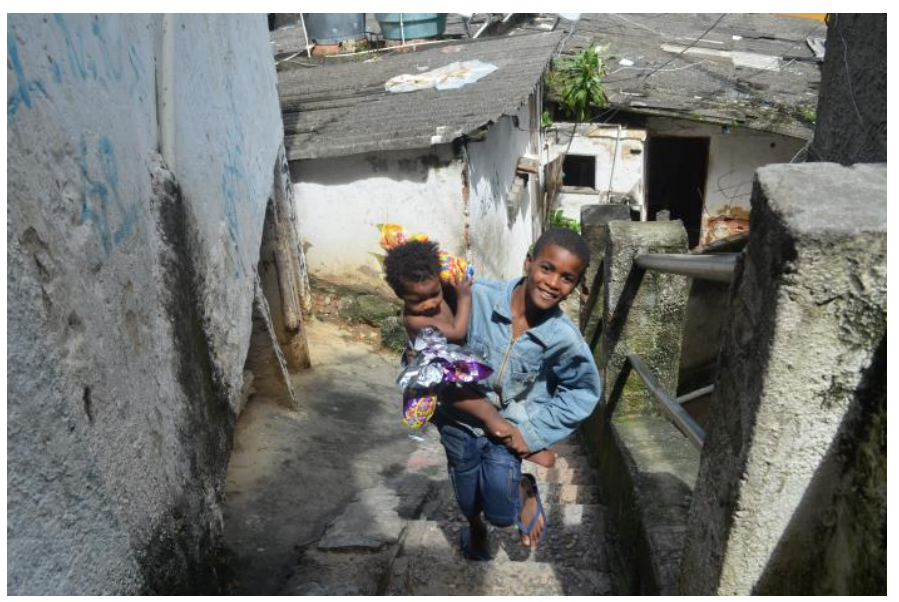

Figura 8 - as crianças da comunidade. (foto do designer)

Os registros fotográficos se assemelham a história em que Pasolini conta sobre sua infância e sobre o mundo que conhecia apenas pela visão de sua janela com uma cortina e dos objetos que faziam parte da sua casa. Esse conjunto formava a linguagem pedagógica das coisas, ou seja era o que o ensinava sobre o mundo e fazia com que ele tivesse o entendimento de que aquele era apenas o mundo que existia ou que os outros mundos eram desprovidos de verdade.

A nossa intenção na captura e seleção das imagens para o livro é justamente de mostrar uma janela sem frestas. Amplamente aberta, pronta a receber conceitos, objetivos, diferenças, sentimentos e transformação, evitando preconceitos buscando mostrar a existência de outra cultura, a que ele nomeia como : linguagem da realidade física de uma periferia urbana.

As fotografias foram classificadas em diferentes temas: tipos característicos de pessoas; infraestrutura; produção cultural e convivência.
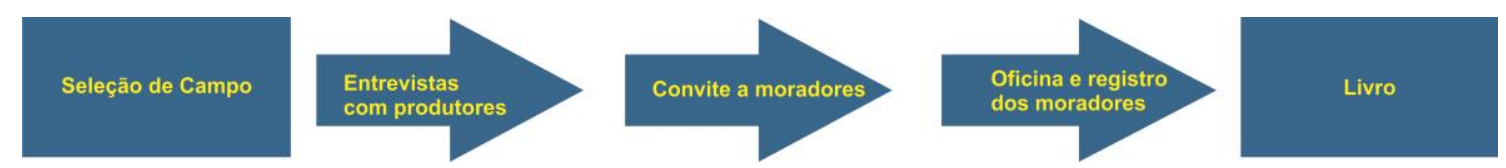
Figura 9 - Gráfico processo do projeto

\section{Livro projeto Gráfico}

O projeto gráfico do livro se inspirou nos conceitos representativos da Rocinha. Suas formas, cores e curvas deram origem a cada escolha na diagramação e layouts adotados. Elegeram-se elementos visuais típicos da materialidade da favela a serem seguidos: textura, sobreposição, irregularidade, cores, assimetria e formas peculiares.

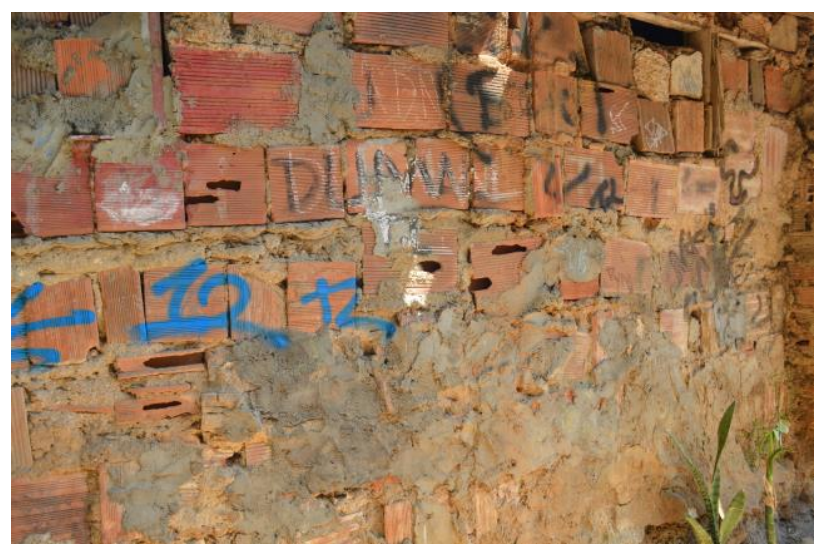

Figura 10 - tijolos e texturas.

Fez-se o uso da angulação e sobreposição dos elementos presentes na página, como: fotografias, boxes e ilustrações. São sempre apresentados assimétricos e sobrepostos, formando camadas de imagens. Essa escolha se deu pela referência das casas e estrutura da formação da própria localidade, visando trazer para o livro um pouco mais do cenário da Rocinha. Com toda essa mistura, irregularidade, cor e sobreposição que juntos formam essa grande textura observada do alto da favela.
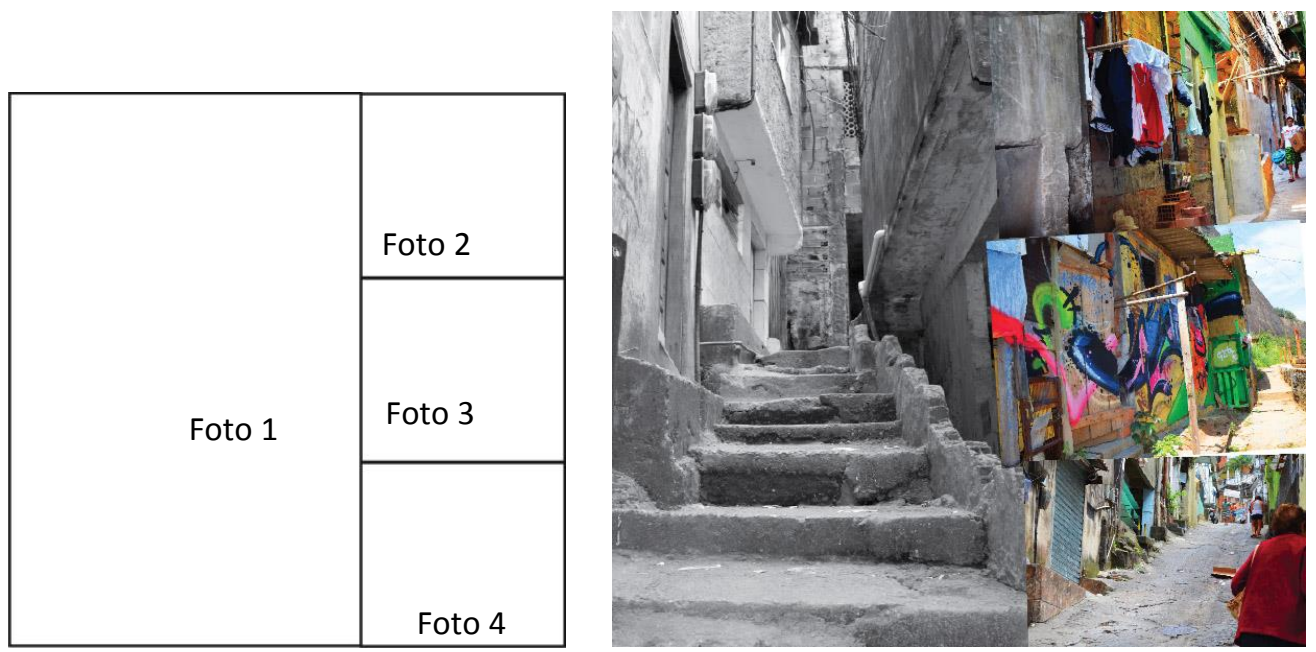

Figura 11 - página do livro mostrando uso das escolhas estéticas.

Para relacionar à mesma dimensão urbana recorremos a técnicas de edição e a pluralidade de expressão e efeitos de fotografia, como o de reticula, pixelado, duotone, mistura de preto e branco com colorido. Tais recursos foram a solução para o uso de imagens em baixa resolução, em especial as imagens antigas que não tinham como ser substituídas ou encontradas em melhor qualidade. 


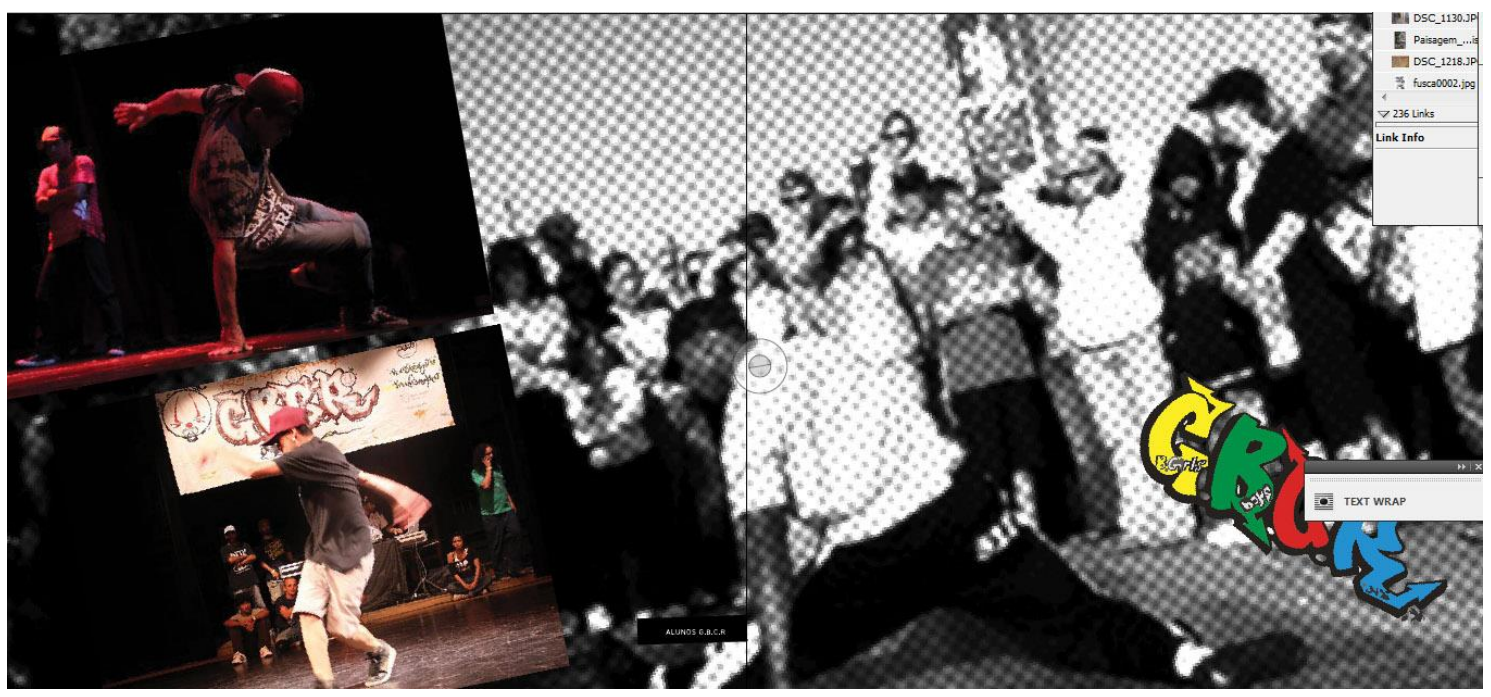

Figura 12 - página do livro mostrando uso das escolhas estéticas.

Também ilustramos alguns elementos que são apresentados em cada uma das produções e outras lustrações são apresentadas no decorrer do livro, além de algumas monotipias, transferências de Xerox, desenhos, e outras técnicas experimentais de ilustração.

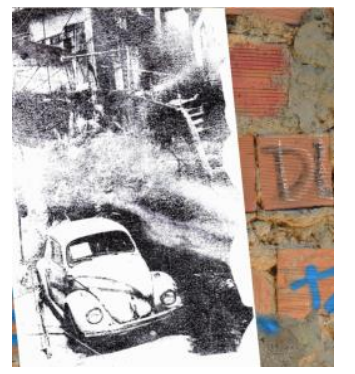

Figura 13 - transf. xerox

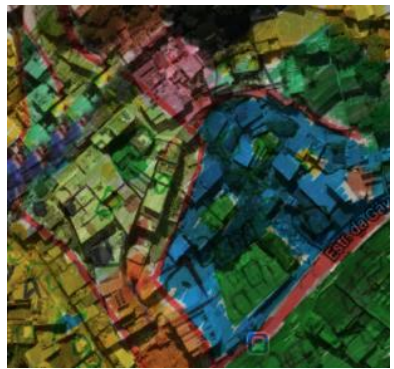

Figura 14- monotipia

As cores usadas no livro foram obtidas a partir das cores mais presentes na comunidade, como o pigmento do tijolo presente na maioria das casas sem revestimento, ou o cinza do cimento, o verde presente na mata, o azul das caixas de agua nas lajes, dentre outras, o que gerou uma cartela de cores. (figura 1 )

\section{Papel político e social}

É a possibilidade da real deflagração de que uma transformação é possível quando as mãos se atrelam no sentido de uma realização do fazer, pelo fazer para obter. Representa, politicamente, o inexorável social em mudança que clama por uma politica sem escamoteio: uma inclusão através da produção cultural.

Esses papéis são mais um elo com a obra de Pasolini que via na leitura de imagens, em sua desnaturalização a verdadeira possibilidade de se fazer política, ou, pelo menos, de dar substrato a ações sociais.

$\mathrm{O}$ projeto teve como ponto de partida o desejo de mostrar à sociedade as qualidades e o potencial humano dos moradores de favela, suas peculiaridades, suas relações de convivência e sua produção cultural, com o objetivo de quebrar preconceitos e o mito de que todo favelado é marginal. 
Buscou-se dar visibilidade à materialidade das produções culturais praticadas pelos moradores, validando que é uma valorosa estratégia para transformação social em diversos campos: geração de emprego e renda; criação de novas áreas, impacto nas atividades econômicas.

A expressão cultural tem o papel fundamental que é o de qualificar o potencial humano; melhorar a autoestima; incentivar as trocas sociais; estimular a cidadania, além de corroborar com os laços de identidade e cooperação e uma tentativa de amenizar os estereótipos e preconceitos sofridos pelos moradores.

A publicação do livro ficou por conta da PUC-RIO que se interessou em distribuir a obra dentro da Universidade com uma tiragem inicial. Após a divulgação do projeto O Jornal do Brasil e Editora Minister ofereceram o convite para publicação em uma tiragem maior do livro que será lançado na Rocinha ainda esse ano, gratuitamente, para que todos possam ter acesso

\section{CONCLUSÕES}

De acordo com Gilberto Velho (2004), a participação sociocultural do homem é um requisito para sua existência: “O homem só existe através da vida cultural e, isolálo desta, mesmo em termos puramente analítico, pode deformar qualquer processo de conhecimento".

Confirma assim o diálogo feito aqui com a semiologia de Pasolini. Vendo nesse projeto de Design um diagnóstico da cultura e sua expressão imagética. As ferramentas de comunicação visual foram inexoráveis nesse processo. Aspectos cromáticos, de texturas ou de composição fotográfica, são o próprio conteúdo, desde que opta-se por uma metodologia que vê na obra de Pasolini uma referencia imprescindível.

Fica claro que assim como em Jovens Infelizes de Pasolini, O grande desafio para o jovem da favela é a incerteza do futuro, é uma vida cercada de obstáculos, onde tem que se enfrentar a desagregação social, a falta de oportunidades e de escolhas. Muitas vezes, fica preso dentro de seu território sem circular pelo resto da cidade, o que aponta a importância da troca dos bens materiais e simbólicos como cultura e arte para possibilitar a integração da periferia com a sociedade. Gilberto Dimenstein (2010) afirma que a pior desigualdade é a falta de conhecimento " A pior das desigualdades é a da informação, do conhecimento. [Ela] acaba se revelando nas mais diferentes formas, na questão da saúde, da cultura, do emprego, da renda." Como Pasolini, ele enxerga as tiranias produzidas por um sistema material.

O projeto introduz as possibilidades de um diálogo original entre a obra de uma autor pouco usado na área do design e dentro de um campo especifico, o estudo das periferias urbanas. 


\section{REFERÊNCIAS}

BONSIEPE, G. Design, cultura e sociedade. São Paulo: Blucher, 2011.

COUTINHO, S. Davison. Um olhar sobre a produção cultural na Rocinha. Rio de Janeiro, Minister, 2013.

DIMENSTEIN, Gilberto. Espaços em Transformação. Revista Continuum Itaú Cultural, São Paulo, p. 32, 2010.

GAMBA JR., Nilton G. Sísifo: Fetiche e Linguagem - Pasolini e a Pós-modernidade naturalizada. In RIBES, Rita e SANTOS, Nubia. Diálogos: Educação e Pesquisa. (No Prelo - 2012)

LAHUD, Michel. A vida clara. Linguagens e realidade, segundo Pasolini. São Paulo, Companhia das Letras/UNICAMP, 1993.

PASOLINI, P. P. Os jovens infelizes. Antologia dos ensaios corsários. São Paulo, Brasiliense, 1990.

PASOLINI, P. P. Empirismo Heretico. Córdoba, Editorial Brujas, 2005.

As últimas palavras do herege. Entrevistas com Jean Duflot. São Paulo, Brasiliense, 1983.

VELHO, Gilberto. Individualismo e Cultura: Notas Para Uma Antropologia Da Sociedade Contemporânea. Rio de Janeiro, Zahar, 1987.

Varal de Lembranças - Histórias da Rocinha. Rio de Janeiro: SEC/MEC/FNDE, 1983. 